\title{
Antibacterial Properties of Sol-Gel Derived $\mathrm{TiO}_{2}$ Nanoparticles
}

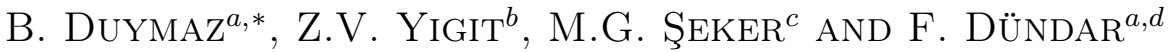 \\ ${ }^{a}$ Nanotechnology Research Center, Gebze Technical University, Cayirova, Kocaeli Turkey \\ ${ }^{b}$ Institute of Physical Metallurgy and Metal Physics, RWTH Aachen University, Aachen, 52056, Germany \\ ${ }^{c}$ Moleculer Biology and Genetic, Gebze Technical University, Cayirova, Kocaeli Turkey \\ ${ }^{d}$ Mechanical Engineering Dept., Meliksah University, Talas, Kayseri, Turkey
}

\begin{abstract}
Efficient synthesis of antibacterial and antifungal titanium dioxide nano powders offers new advanced properties and opportunities for industrial applications. In the present study, $\mathrm{TiO}_{2}$ nano particles were synthesized by solgel method using aqueous and alcoholic solutions of titanium tetraisopropoxide (TTIP). The effects of solvent type, support material (calcite, talk, zinc borate, silica) and drying temperature on antibacterial/antifungal and structural properties namely the average particle size and surface area of titania particles were investigated.
\end{abstract}

DOI: 10.12693/APhysPolA.129.872

PACS/topics: 82.56.Lz, 81.20.Fw, 87.19.xb, 81.07.--b

\section{Introduction}

Nano-sized $\mathrm{TiO}_{2}$ particles have received great attention in industry since they have potential applications in several products and systems such as technological paints, biomaterials, photovoltaic cells, air and water purification systems, etc. These applications generally depend on antibacterial, self cleaning and environmentally clean properties of $\mathrm{TiO}_{2}$ arising from its band gap characteristics $[1-3]$.

Development of antibacterial materials has a primary importance for researchers due to the strong relation with human health care. Microorganism annihilation efficiency of these materials helps people to overcome many infectious diseases. Nano-scale synthesis or mixing with antibacterial agents are the most known methods to make materials antibacterial $[4,5]$.

The sol-gel process has become a frequently preferred method, needing a simple equipment setup and low synthesis temperatures. Furthermore, the final product might be shaped into several structural forms by controlling gelation conditions and can be supported with different materials. Sol-gel process results in a crystalline network, which is generaly based on the precursor hydrolysis, polycondensation, the gel condensation and drying/calcination [6].

In this study, $\mathrm{TiO}_{2}$ nanoparticles were synthesized successfully using sol-gel method. Variations in composition and mean particle size are originated from different drying temperatures, solvents and support materials used in the process. Consequences of those changes on the structural and antibacterial properties have been investigated.

*corresponding author; e-mail: duymzburcu@gmail.com

\section{Experimental \\ 2.1. Preparation of titania particles}

Titania nano particles were prepared by a sol-gel process using two different solvents, water and ethanol. Titanium (IV) tetraisopropoxide was used as the titania precursor in both methods.

In the first method the titania precursor was dissolved in ethanol and the oxidation reaction was catalyzed by adding nitric acid to the solvent. The synthesis was conducted at room temperature. The titania gel was dried for 24 hours at $90^{\circ} \mathrm{C}$ and ground afterwards to obtain fine powders.

As the second method, the titania precursor was dissolved in distilled water. Similarly, nitric acid was used as the catalyst for the oxidation reaction. The synthesis was conducted at $50^{\circ} \mathrm{C}$ to obtain homogeneity. Then the titania sol was dried and ground similar to the first method.

Titania nanoparticles were synthesized on silica prepared from (PTMS), calcite, talk and zinc borate to lower the cost of the final product. The support material weight ratio was kept at $20 \mathrm{wt} \%$ for all syntheses. Silica, calcite, talk and zinc borate were present in the solvent during nano titania oxidation reaction to obtain supported titania particles. Unfortunately the water based method didn't respond well to the presence of support material during the catalytic reaction and uncontrollable foam formation was observed. Ethanol based method was used for supported titania preparation.

\subsection{Antibacterial activity test}

The agar diffusion method was selected to observe the antibacterial and antifungal behavior of custom made supported and unsupported titania particles. In this method, a small groove is prepared on a sterile Mueller Hilton Agar (MHA) by a sterile glass pipette. The surface of the agar is streaked with different bacterial 
suspensions. The agars were placed in a petri dish and divided into six sections to observe the antibacterial and antifungal behavior of six different titania nanoparticles. Staphylococcus aureus [(ATCC-American Type Culture Collection) 29213], Candida albicans (ATCC 10231), and Escherichia coli (ATCC 8739) were used as bacterial and fungal suspensions. The bacteria concentration was kept constant by adding $100 \mu \mathrm{l}$ of 0.5 McFarland [about $108 \mathrm{cfu}$ (colony forming unit)/ml] bacterial suspension into sterile serum physiologic (SSF) water $(0.85 \% \mathrm{w} / \mathrm{v})$. The bacteria/fungal concentration was diluted from $10-1$ to $10-8$ by an nephelometer. $100 \mu \mathrm{l}$ of diluted bacterial/fungal suspensions were inoculated on MHA for all bacterial strains. Inoculated agars were incubated at $37^{\circ} \mathrm{C}$ for 24 hours. After the incubation process initial cell number was calculated as $108 \mathrm{cfu} / \mathrm{ml}$ for Escherichia coli (E. coli), $3 \times 108 \mathrm{cfu} / \mathrm{ml}$ for Staphylococcus aureus (S. aureus) and $5 \times 105 \mathrm{cfu} / \mathrm{ml}$ for Candida albicans (C. albicans).

Aqueous solutions of the prepared supported and unsupported titania nanoparticles were prepared with distilled water at different concentrations $(1,5,10,15$ and 20 wt.\%). The grooves on MHAs were filled with $100 \mu \mathrm{l}$ of these aqueous solutions for all bacterial/fungal strains. Sterile distilled water was used as a negative control. The titania added MHAs were incubated at $37^{\circ} \mathrm{C}$ for 24 hours. The experiment was repeated two times for each bacterial/fungal strain. The inhibition zone around the groove was monitored to understand the antibacterial behavior of the prepared nano titania particle [4].

\section{Results}

\subsection{Analytical measurements}

Titania particles synthesized by the sol-gel method were characterized by analytical instruments and methods like Dynamic Light Spectroscopy (DLS) and Brunauer Emmett Teller (BET) Surface Area Measurement. Titania nanoparticles were diluted in deionized water for DLS analysis. Particle sizes for various supported and unsupported $\mathrm{TiO}_{2}$ particles were found to be between $50 \mathrm{~nm}$ and $5 \mu \mathrm{m}$. Mineral (Calcite, Talc, Silica and ZnB) added titania particles were much larger than unsupported titania particles. Among others ZnB supported $\mathrm{TiO}_{2}$ particles had a lower particle size of $165 \mathrm{~nm}$, which was expected since average particle size of pure $\mathrm{ZnB}$ was $150 \mathrm{~nm}$. The particle distribution of various supported and unsupported titania particles are shown in Fig. 1 and the average particle sizes are summarized in Table I.

Surface areas of supported and unsupported titania particles were measured with BET method. Surface areas of support materials and unsupported titania particles were measured at first. Surface area of titania particles synthesized with the water based method were found to be $540.76 \mathrm{~m}^{2} / \mathrm{g}$, whereas surface areas of calcite, talc and $\mathrm{ZnB}$ were found to be $5.11 \mathrm{~m}^{2} / \mathrm{g}, 14.39 \mathrm{~m}^{2} / \mathrm{g}$ and $1057.5 \mathrm{~m}^{2} / \mathrm{g}$, respectively. The surface area of calcite supported titania was found to be $248.55 \mathrm{~m}^{2} / \mathrm{g}$. Similarly, the surface area of talc supported titania was found

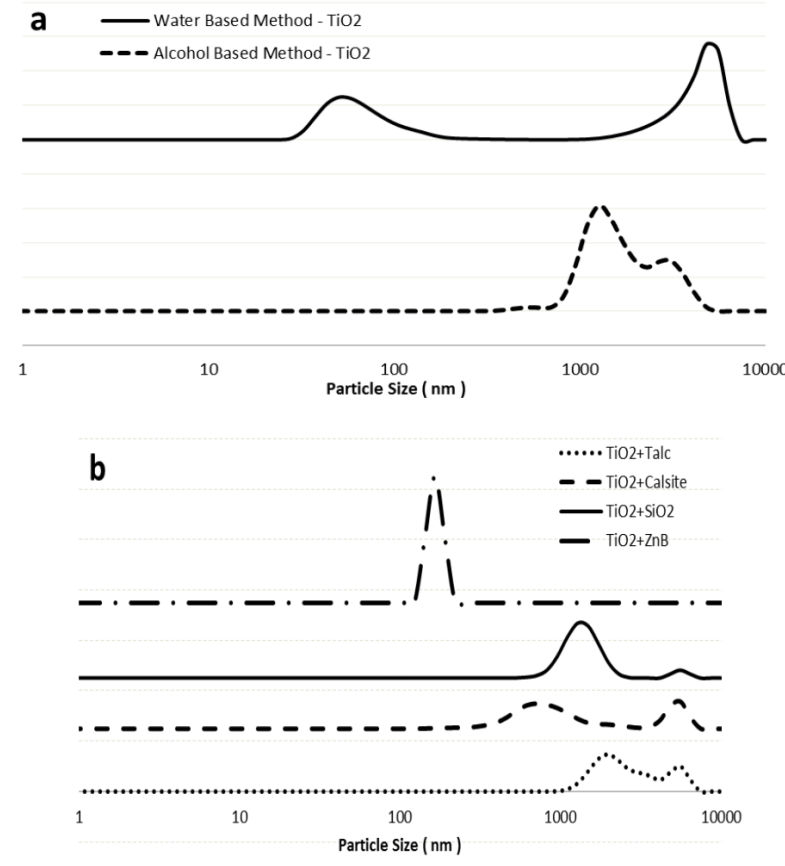

Fig. 1. Particle size distribution of supported and unsupported titania particles.

TABLE I

Average particle size values of supported and unsupported titania particles.

\begin{tabular}{c|c|c}
\hline \hline Support type & Synthesis method & $\begin{array}{c}\text { Average particle } \\
\text { size [nm] }\end{array}$ \\
\hline Unsupported & Water Based & 2641 \\
Unsupported & Alcohol Based & 1858 \\
Calcite & Alcohol Based & 2094 \\
Talc & Alcohol Based & 3009 \\
Silica & Alcohol Based & 1634 \\
ZnB & Alcohol Based & 165
\end{tabular}

to be $271.18 \mathrm{~m}^{2} / \mathrm{g}$. Finally, the surface area of $\mathrm{ZnB}$ supported titania was found to be $497.46 \mathrm{~m}^{2} / \mathrm{g}$. All of the supported titania particles had lower surface area in comparison with unsupported titania particles, however adding a support material is required to reduce the costs.

\subsection{Antibacterial behavior observations}

Supported and unsupported titania particles dissolved in distilled water were dropped on agars inoculated by three different bacterial strains; E. coli, S. aureus and C. albicans. Different titania concentrations from 1 wt.\% to 20 wt.\%, for all titania types, were tested with the agar diffusion method. Inhibition zone was only monitored for 20 wt. $\% \mathrm{TiO}_{2}$ concentration. The agar diffusion method results for the selected titania particles are shown in Table II.

Inhibition zone couldn't be observed for talc, calcite and silica supported titania particles, however ZnB supported titania particles showed antibacterial/antifungal 


\section{TABLE II}

Inhibition zones of $\mathrm{TiO}_{2}$ and $\mathrm{TiO}_{2}$ with $\mathrm{ZnB}$ against E. coli, S. aureus, C. Albicans.

\begin{tabular}{|c|c|c|c|}
\hline \multirow{3}{*}{ Strains } & \multicolumn{3}{|c|}{ Inhibition zones $[\mathrm{mm}]$} \\
\hline & \multicolumn{2}{|c|}{ Unsupported $\mathrm{TiO}_{2}(20 \%)$} & \multirow{2}{*}{$\begin{array}{c}\mathrm{TiO}_{2} \\
\text { with } \mathrm{ZnB} \\
{[20 \%]}\end{array}$} \\
\hline & $\begin{array}{c}\text { Alcohol } \\
\text { based method }\end{array}$ & $\begin{array}{c}\text { Water } \\
\text { based method }\end{array}$ & \\
\hline E. coli & 8 & - & 30 \\
\hline S. aureus & 14 & 20 & 40 \\
\hline C. albicans & - & 30 & 60 \\
\hline
\end{tabular}

behavior for all strains. On the other hand, unsupported titania particles prepared with the water based method and ethanol based method both showed antibacterial behavior against certain bacteria. However, their antibacterial behaviors were not as strong as that of $\mathrm{ZnB}$ supported titania particles. The inhibiton zone diameters of titania particles which showed antibacterial property is summarized in Table II.

Scanning Electron Microscope (SEM) image of the synthesized titania nano powders is shown in Fig. 2.

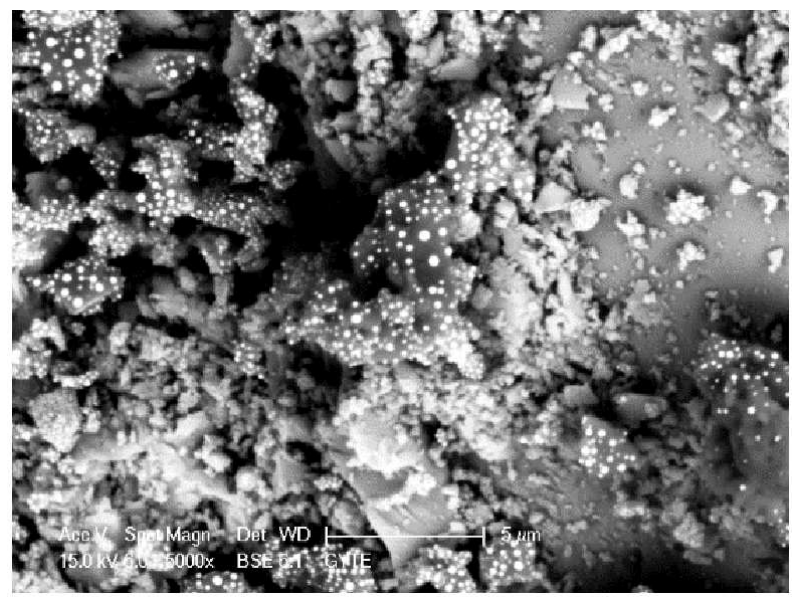

Fig. 2. SEM image of $\mathrm{TiO}_{2}$ particles.

\section{Conclusions}

Antibacterial and antifungal properties of supported and unsupported titania nanoparticles synthesized with water and alcohol based sol gel methods were tested in this study. ZnB supported titania particles showed the highest antibacterial and antifungal activity. Additionally unsupported titania particles synthesized with the alcohol-based method showed antibacterial behavior against E. coli and S. aureus up to a certain extent. Similarly unsupported titania particles synthesized with the water-based method showed antibacterial behavior against $\mathrm{S}$. aureus and antifungal behavior against $\mathrm{C}$. albicans.

\section{Acknowledgments}

This project (SANTEZ 1343.STZ.2012-1) was founded by Kardelen Boya and Republic of Turkey, Ministry of Science, Industry and Technology. We would like to thank for their support.

\section{References}

[1] D.P. Macwan, P.N. Dave, S. Chaturvedi, J. Mater. Sci. 46, 3669 (2011).

[2] D. Mrinmoy, P.S. Ghosh, V.M. Rotello, Adv. Mater. 20, 4225 (2008).

[3] M. Dubey, H. He, Morphological and Photovoltaic Studies of $\mathrm{TiO}_{2}$ NTs for High Efficiency Solar Cells, INTECH Open Access Publisher, 2012.

[4] G. Fu, P.S. Vary, C-T. Lin, J. Phys. Chem. B 109 , 8889 (2005).

[5] R. Singh, H.S. Nalwa, J. Biomed. Nanotechnol. 7, 489 (2011).

[6] T. Sugimoto, X. Zhou, A. Muramatsu, J. Colloid Interf. Sci. 259, 43 (2003). 